ANNALES

UNIVERSITATIS MARIAE CURIE-SKŁODOWSKA

LUBLIN - POLONIA

VOL. LXXI, 2

SECTIO AA

2016

\title{
The determination of titanium contained in Tytanit biostimulant employed to improve crops performance in natural environmental samples
}

\author{
Joanna Wasąg* and Małgorzata Grabarczyk \\ Department of Analytical Chemistry and Instrumental Analysis, \\ Faculty of Chemistry, Maria Curie-Skłodowska University, \\ Maria Curie-Sktodowska Sq. 3, 20-031 Lublin, Poland \\ "email:jkolcz@op.pl
}

The purpose of this work was to determinate the amount of titanium in samples spiked with crop biostimulant Tytanit. The measurements were conducted using adsorptive stripping voltammetry (AdSV). The titanium complex with chloranilic acid was accumulated on mercury film silver based electrode $(\mathrm{Hg}(\mathrm{Ag}) \mathrm{FE})$ at the potential $-0.3 \mathrm{~V}$. The analysis of natural water samples enriched with Tytanit, collected in the eastern part of Poland confirms that this procedure is fast and essential for the determination of titanium in environmental water samples.

\section{INTRODUCTION}

The titanium is an element which affects on plant growth. Titanium content in the soil is $0.17 \%$ and occurs in the form of insoluble compounds. Its content in plants is low from 10 to $120 \mathrm{mg} / \mathrm{kg}$ dry weight [1], for this reason there is a need to deliver this element to plant. Tytanit is a preparation which allows such process because it contains significant 
amount of easily assimilated by plants titanium $\left(8.5 \mathrm{~g} / \mathrm{dm}^{3} \mathrm{Ti}(\mathrm{IV})\right)$ and it is employed to improve crops performance.

The largest biological benefits brought by the application of Tytanit are:

- to increase yields and the synthesis of assimilation pigments,

- to activate metabolic processes during the growth and development of plants,

- to increase the content of chlorophyll in leaves, which has a positive effect on the yield of the crops.

Widespread use of Tytanit in the cultivation of plants, the titanium compounds get into the soil and next to the ground water and living organisms, causing that there is a need to monitor trace levels of titanium in the natural environmental samples for the prevention of possible contamination and control production of this element $[2,3]$.

The aim of these studies was to determine the amount of titanium in natural water samples with complex organic matrix enriched with crop biostimulant Tytanit. The analysis was performed using adsorptive stripping voltammetry technique (AdSV). The procedure exploit chloranilic acid like a complexing agent and mercury film silver base electrode $(\mathrm{Hg}(\mathrm{Ag}) \mathrm{FE})$ as a working electrode [4]. During accumulation step Ti(IV)-chloranilic acid complexes were adsorbed onto electrode surface and next differential pulse voltammogram was recorded, while the potential was scanned from $-0.4 \mathrm{~V}$ to $-0.9 \mathrm{~V}$, with the intensity of the obtained peak directly proportional to the concentration of $\mathrm{Ti}(\mathrm{IV})$ in the sample [5].

\section{MATERIAL AND METHODS}

\subsection{Apparatus}

Experiments were conducted using a $\mu$ Autolab PGSTAT 10 analyzer (Utrecht, The Netherlands) with $\mathrm{Hg}(\mathrm{Ag}) \mathrm{FE}$ as a working electrode (the construction was described in the paper [4]), a Pt auxiliary electrode and an $\mathrm{Ag} / \mathrm{AgCl}$ (in saturated $\mathrm{NaCl}$ ) reference electrode. The 
solutions were deoxygenated with high-purity nitrogen for $5 \mathrm{~min}$ prior to each measurement and kept under nitrogen atmosphere during the analyzes.

\subsection{Reagents}

All chemicals used were of analytical reagent grade or Suprapur. A stock standard solution of $1 \mathrm{~g} / \mathrm{dm}^{3}$ of $\mathrm{Ti}(\mathrm{IV})$ was obtained from Fluka (Buchs, Switzerland). The solutions of Ti(IV) of lower concentrations were prepared by dilution of the stock solution as required. The Tytanit was obtained from Intermag and it was purchased at garden center. To prepare a solution of $1 \cdot 10^{-4} \mathrm{~mol} / \mathrm{dm}^{3}$ Tytanit, $5.65 \mathrm{~mm}^{3}$ Tytanit preparation $\left(8.5 \mathrm{~g} / \mathrm{dm}^{3} \mathrm{Ti}(\mathrm{IV})\right)$ and addition of $0.5 \mathrm{~cm}^{3} 1 \mathrm{~mol} / \mathrm{dm}^{3} \mathrm{HNO}_{3}$, dissolved in water up to $10 \mathrm{~cm}^{3}$. Chloranilic acid was obtained from Fluka and prepared daily by dissolving $0.042 \mathrm{~g}$ chloranilic acid in $20 \mathrm{~cm}^{3}$ of water. Received concentration of chloranilic acid was $1 \cdot 10^{-2} \mathrm{~mol} / \mathrm{dm}^{3}$. Acetate buffers were prepared from Suprapur $\mathrm{CH}_{3} \mathrm{COOH}$ and $\mathrm{NaOH}$ obtained from Merck. All solutions were prepared using triply distilled water.

\subsection{Sample preparation}

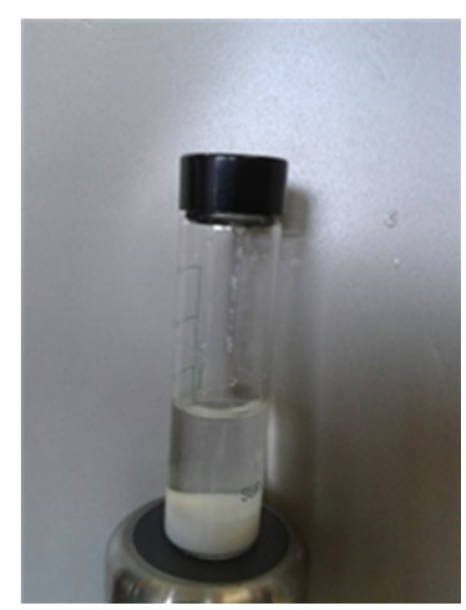

Fig. 1. The sample solution with addition Amberlite XAD-7 resin [6].
The procedure was applied to the determination of titanium in natural water samples collected from the eastern part of Poland, Lake Zemborzyce and Bystrzyca River and also in tap water and rain water spiked with Tytanit. The samples were stored in polypropylene bottles at the temperature $6^{\circ} \mathrm{C}$. In the case of analysis of environmental samples with organic-rich matrices the preliminary mixing with Amberlite XAD-7 resin was applied before analysis. The mixing with Amberlite XAD-7 resin, gives a superb effect as concerns the elimination of 
organic matrix interferences [7-11]. In this case, $0.5 \mathrm{~g}$ of resin was added to the sample solution with $4.5 \mathrm{~cm}^{3}$ environmental water, $5 \mathrm{~cm}^{3}$ triply distilled water, $0.5 \mathrm{~cm}^{3}$ supporting electrolyte $\left(\mathrm{CH}_{3} \mathrm{COOH}\right)$ and proper concentration of $1 \cdot 10^{-4} \mathrm{~mol} / \mathrm{dm}^{3}$ Tytanit solution. Before performing measurement, the solution has been mixed with magnetic stirrer for 5 minutes. Fig. 1 presents sample solution after the addition Amberlite XAD-7 resin. In this step, organic substances adsorb on resin and titanium remains in the solution.

\subsection{The adsorptive stripping procedure of titanium in Tytanit determination}

After appropriate sample preparation and mixing with Amberlite XAD-7 resin, the $1 \mathrm{~cm}^{3}$ of the solution was pipette into the electrochemical cell. Consecutively, $500 \mathrm{~cm}^{3}$ of $1 \cdot 10^{-2} \mathrm{~mol} / \mathrm{dm}^{3}$ chloranilic acid, $0.95 \mathrm{~cm}^{3}$ of $1 \mathrm{~mol} / \mathrm{dm}^{3} \mathrm{CH}_{3} \mathrm{COOH}$ and $7.55 \mathrm{~cm}^{3}$ of triply distilled water were added and after deaeration (lasting 5 minutes), a voltammetric measurement was performed. The accumulation potential was $-0.3 \mathrm{~V}$ for $30 \mathrm{~s}$ and after the equilibration time of $5 \mathrm{~s}$, the differential pulse voltammogram was recorded. The potential was scanned from $-0.4 \mathrm{~V}$ to $-0.9 \mathrm{~V}$, while the intensity of the obtained peak was directly proportional to the concentration of Ti(IV) in Tytanit in the sample. The next samples were spiked with different concentration of standard solution of $\mathrm{Ti}(\mathrm{IV})$ and the measurement was conducted similarly as before. The standard addition method was applied to calculate the recovery values.

\section{RESULT AND DISCUSSION}

Introductory studies using $\mathrm{Hg}(\mathrm{Ag}) \mathrm{FE}$ and chloranilic acid in aceticacetate solution for determination Ti(IV) showed that it is possible to obtain a reduction peak of complex $\mathrm{Ti}(\mathrm{IV})$-chloranilic acid at the differential pulse voltammogram [5]. Consequently, the optimization of experimental parameters in the determinations of titanium in Tytanit 
(such as $\mathrm{pH}$ and concentration of supporting electrolyte, chloranilic acid concentration, potential and time of accumulation) was performed.

\subsection{Effect of $p H$ and concentration of supporting electrolyte}

The influence of the $\mathrm{pH}$ of the supporting electrolyte on the titanium voltammetric signal in the proposed procedure was examined. The measurements were performed for solutions containing a fixed concentration of $3 \cdot 10^{-7} \mathrm{~mol} / \mathrm{dm}^{3}$ Tytanit, $1 \cdot 10^{-3} \mathrm{~mol} / \mathrm{dm}^{3}$ chloranilic acid and $0.1 \mathrm{~mol} / \mathrm{dm}^{3} \mathrm{CH}_{3} \mathrm{COOH} / \mathrm{CH}_{3} \mathrm{COONa}$ with variable $\mathrm{pH}$ in the range from 3.0 to $6.0\left(\mathrm{CH}_{3} \mathrm{COOH}\right.$ or $\mathrm{NaOH}$ were used to obtain the required medium) or acetic acid $(\mathrm{pH}=2.9)$.

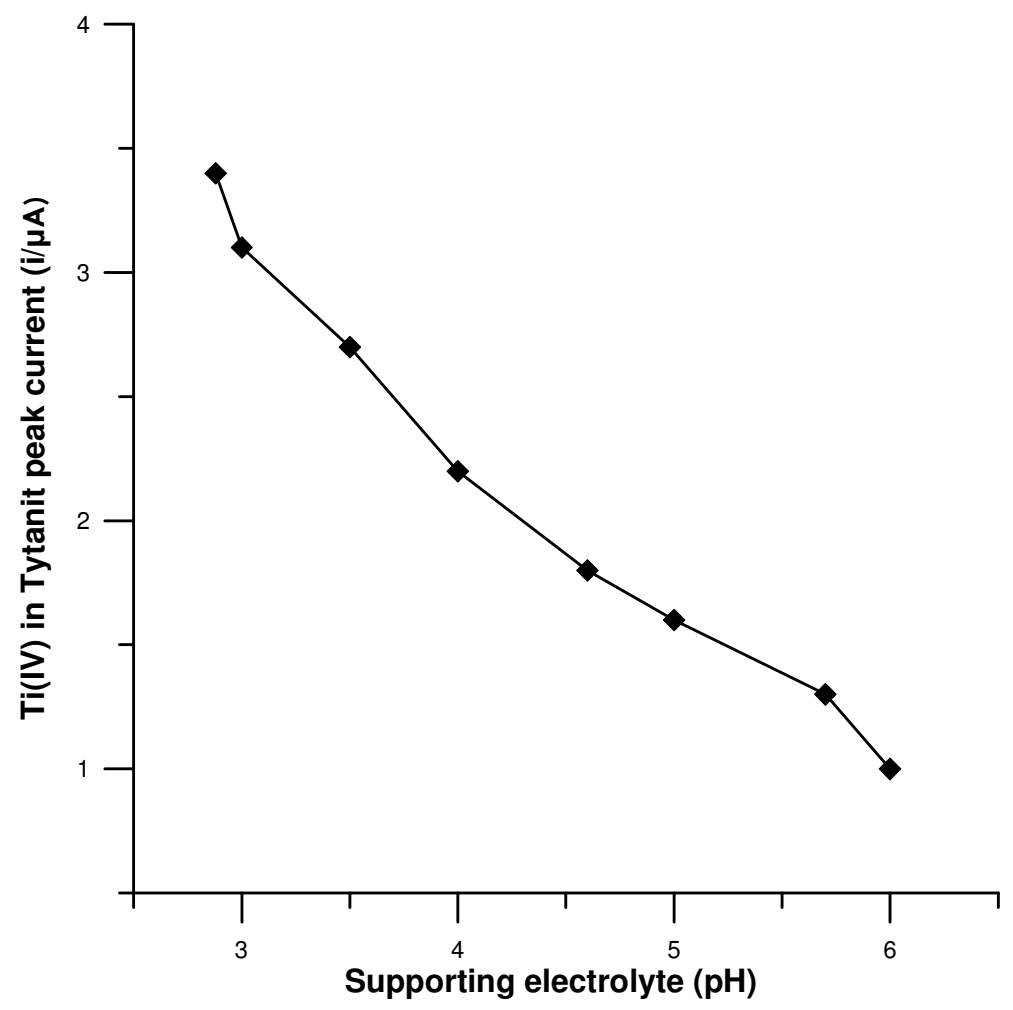

Fig. 2. The influence of $\mathrm{pH}$ on the peak current of $\mathrm{Ti}(\mathrm{IV})$ in Tytanit. Composition of solution $3 \cdot 10^{-7} \mathrm{~mol} / \mathrm{dm}^{3}$ Tytanit, $1 \cdot 10^{-3} \mathrm{~mol} / \mathrm{dm}^{3}$ chloranilic acid, $0.1 \mathrm{~mol} / \mathrm{dm}^{3} \mathrm{CH}_{3} \mathrm{COOH} / \mathrm{CH}_{3} \mathrm{COONa}$ or $\mathrm{CH}_{3} \mathrm{COOH}$. Accumulation potential and time $-0.3 \mathrm{~V}$ for $30 \mathrm{~s}$. 
The obtained data presented in Fig. 2 suggesting that the $\mathrm{pH}$ of the supporting electrolyte equal 2.9 should be chosen as the $\mathrm{pH}$ of the best efficiency of adsorption of the Ti(IV)-chloranilic acid complex on $\mathrm{Hg}(\mathrm{Ag}) \mathrm{FE}$ electrode. The extreme signal was obtained in $0.1 \mathrm{~mol} / \mathrm{dm}^{3}$ acetic acid. With the increase of $\mathrm{pH}$ (the use of acetate buffers) the signal of titanium in Tytanit was decreased.

\subsection{Effect of chloranilic acid concentration}

Chloranilic acid concentration had a considerable influence on the sensitivity of the methods. The effect of complexing agent concentration was studied in the range $5 \cdot 10^{-6} \mathrm{~mol} / \mathrm{dm}^{3}$ to $2 \cdot 10^{-3} \mathrm{~mol} / \mathrm{dm}^{3}$ for $3 \cdot 10^{-7} \mathrm{~mol} / \mathrm{dm}^{3}$ of Tytanit, while the other standard measuring conditions remained constant $\left(0.1 \mathrm{~mol} / \mathrm{dm}^{3}\right.$ acetic acid, $\left.\mathrm{pH}=2.9\right)$. The results show that the peak of $\mathrm{Ti}(\mathrm{IV})$ increased with increasing chloranilic acid concentration up to $1 \cdot 10^{-3} \mathrm{~mol} / \mathrm{dm}^{3}$ and finally it was constant, so the concentration of $1 \cdot 10^{-3} \mathrm{~mol} / \mathrm{dm}^{3}$ was adopted as the optimum for further experiments.

\subsection{Conditions of accumulation potential and time}

The study of the influence of the accumulation potential on the peak currents was investigated using a solution containing previously chosen concentrations $3 \cdot 10^{-7} \mathrm{~mol} / \mathrm{dm}^{3}$ of Tytanit, $0.1 \mathrm{~mol} / \mathrm{dm}^{3}$ acetic acid and $1 \cdot 10^{-3} \mathrm{~mol} / \mathrm{dm}^{3}$ of chloranilic acid. The potential was changed over the range of $-0.5 \mathrm{~V}$ to $0.2 \mathrm{~V}$ and obtained data showed that the peak current was almost stable in the range from $-0.4 \mathrm{~V}$ to $-0.2 \mathrm{~V}$ whereas for another values (higher or lower) it slowly decreased, so the accumulation potential equal $-0.3 \mathrm{~V}$ was selected for further experiments.

Accumulation time is one of the parameters that have a significant effect on sensitivity in adsorptive stripping voltammetry procedures. The effect of accumulation time on $3 \cdot 10^{-7} \mathrm{~mol} / \mathrm{dm}^{3}$ Tytanit peak currents was examined in the range from $10 \mathrm{~s}$ to $90 \mathrm{~s}$, while other standard measuring conditions remained constant (accumulation potential $-0.3 \mathrm{~V}$ ). The value of the voltammetric peak currents increased with accumulation time to $30 \mathrm{~s}$, in the case of longer accumulation times the peak current of Tytanit 
decreased insignificantly as shown in Fig. 3. On the basis of these result the accumulation time of $30 \mathrm{~s}$ was chosen.

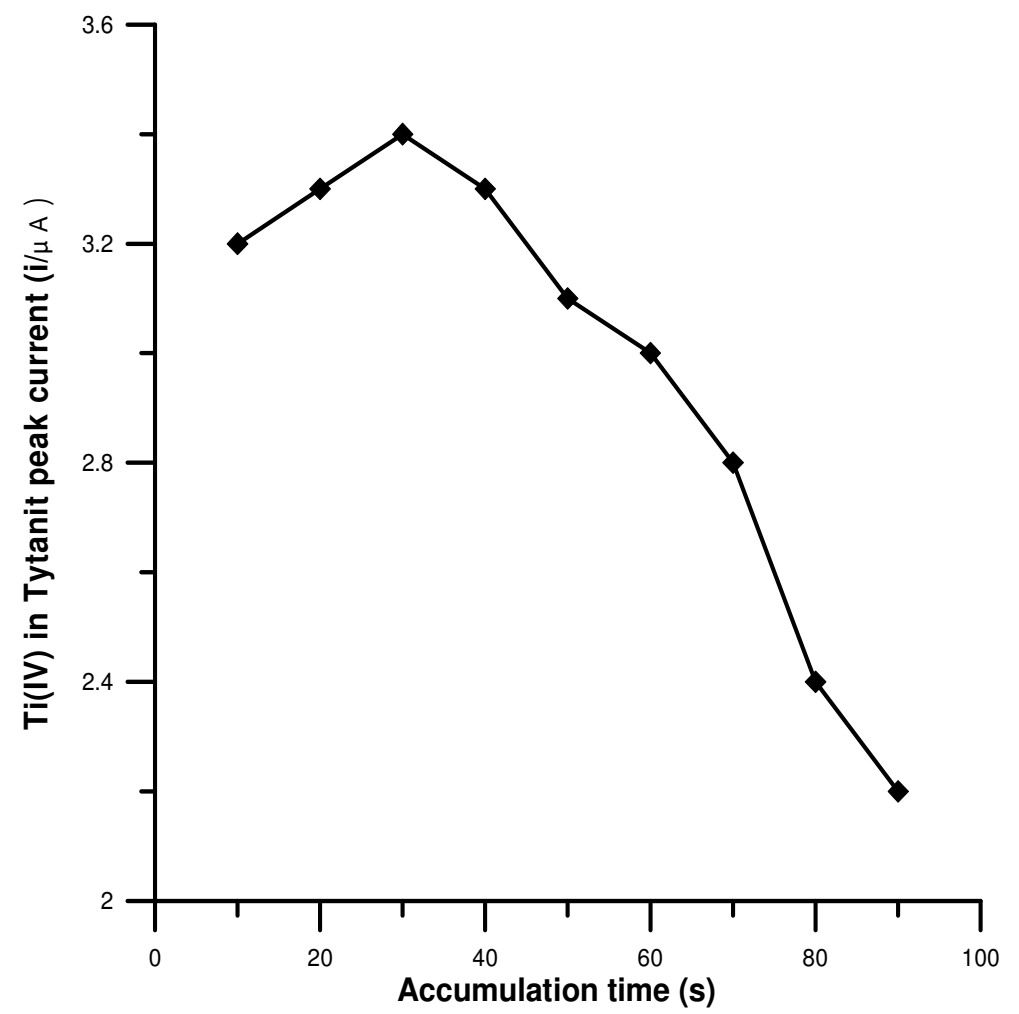

Fig. 3. The influence of accumulation time on the $3 \cdot 10^{-7} \mathrm{~mol} / \mathrm{dm}^{3} \mathrm{Ti}(\mathrm{IV})$ in Tytanit peak current. Accumulation potential $-0.3 \mathrm{~V}$.

\subsection{The calibration graph}

The linear range for Ti(IV) in Tytanit determination was evaluated under the optimum conditions for accumulation times $30 \mathrm{~s}$. The peak currents were found to increase linearly with $\mathrm{Ti}(\mathrm{IV})$ in Tytanit concentration over the range of $3 \cdot 10^{-8}-3 \cdot 10^{-6} \mathrm{~mol} / \mathrm{dm}^{3}$ with the correlation equation: $y=3.45 x-0.38$, where $y$ and $x$ are the peak current $(\mu \mathrm{A})$ and $\mathrm{Ti}(\mathrm{IV})$ concentration $\left(\mu \mathrm{mol} / \mathrm{dm}^{3}\right)$, respectively. The linear correlation coefficient was $r=0.998$. The detection limit estimated from three times standard deviation for the lowest studied Ti(IV) in Tytanit concentration and accumulation time $30 \mathrm{~s}$ was about $5.2 \cdot 10^{-9} \mathrm{~mol} / \mathrm{dm}^{3}$. 


\subsection{Analytical application}

As it is generally known, organic compounds present in the matrix of natural samples adversely affect at adsorptive stripping voltammetric methods, producing a decrease or total decay of the peak currents of the determined analyte. In the proposed procedure of $\mathrm{Ti}(\mathrm{IV})$ contained in Tytanit determination the influence of different types of natural environmental water were precisely investigated. It is important to analyze these samples because Ti(IV) can penetrate into the soil and then to the water. An additional challenge for us resulting from the interferences from environmental samples was the elaboration of a simple, cheap and fast way of its elimination.

The natural environmental water samples may contain significant amounts of organic matrix or different types of surfactants. To examine the impact of these substances on the measurements as the representatives of particular types of compounds were selected humic acids (HA), fulvic acids (FA), natural organic matter (NOM), Triton X-100, SDS and CTAB. All of these substances can prevent conducting the experiment because they can be adsorbed on the electrode surface or can be associated with determined substance. To avoid these troubles during the measurement, the specific procedure was introduced as an additional step of the experiment.

It was proven in earlier papers that a simple, cheap and quick way to eliminate the interferences of organic substances in voltammetric determination is previous mixing of the analyzed sample with Amberlite XAD-7 resin [7-11]. Furthermore, in the case of the present procedure the addition to the sample of XAD-7 resin to allow elimination of the above-mentioned interferences was proposed. The measurements were performed as described previously in chapter 2.4. Next, after sedimentation of resin the solution was transferred to a voltammetric cell and the measurements were performed by standard addition method. Previous studies have shown that the examined environmental samples do not contain titanium or its content is below the detection limit, so not obtained analytical signals [5]. All results were obtained in three replicates to ensure reproducibility. The recovery values of every measurement were calculated about $100 \%$ indicating good accuracy of the 
proposed method. Table 1 shows the result of titanium in Tytanit determination in natural water samples using procedure mixing with resin.

Table 1. Analytical result of titanium contained in Tytanit determination in natural water samples after using procedure with preliminary mixing with Amberlite XAD-7 resin.

\begin{tabular}{ccccc}
\hline Sample & $\begin{array}{c}\text { Tytanit } \\
\text { added } \\
{[\mathrm{nmol} / \mathrm{dm} 3]}\end{array}$ & $\begin{array}{c}\text { Tytanit } \\
\text { found } \\
{[\mathrm{nmol} / \mathrm{dm} 3]}\end{array}$ & $\begin{array}{c}\text { Recovery } \\
{[\%]}\end{array}$ & $\begin{array}{c}\text { RSD } \\
(\mathrm{n}=3)[\%]\end{array}$ \\
\hline Bystrzyca & 5 & 4.65 & 93 & 6.2 \\
River & 10 & 10.30 & 103 & 5.6 \\
& 20 & 22.00 & 110 & 5.3 \\
Lake & 5 & 4.85 & 97 & 5.7 \\
Zemborzyce & 10 & 9.50 & 95 & 4.8 \\
& 20 & 20.40 & 102 & 5.2 \\
Tap water & 5 & 5.00 & 100 & 5.0 \\
& 10 & 11.10 & 111 & 5.2 \\
& 20 & 20.40 & 102 & 4.8 \\
Rain water & 5 & 4.65 & 93 & 5.3 \\
& 10 & 8.40 & 84 & 4.7 \\
& 20 & 17.60 & 88 & 5.6 \\
\hline
\end{tabular}

The recovery from Lake Zemborzyce water without using the procedure mixing with resin were between $38 \%$ and $63 \%$ and the recovery for measurement using preliminary mixing with resin were between $95 \%$ and $102 \%$. The recovery from Bystrzyca River water without mixing with resin were between $65 \%$ and $76 \%$ and with the procedure using mixing with resin were between $93 \%$ and $110 \%$, from rain water recovery for measurement without mixing with resin ranges from $17 \%$ to $41 \%$ and for measurement using this procedure ranges from $84 \%$ to $93 \%$. The recovery from tap water without using procedure 
preliminary mixing with resin ranges from $43 \%$ to $78 \%$ and with procedure mixing with resin recovery ranges from $100 \%$ to $111 \%$. The obtained data present the effectiveness of the developed procedure using resins by adsorption properties. Therefore, it is possible to see a large improvement of signal, compared to measurements without the use of resins, which proves their efficacy in eliminating the interference that may occur in environmental samples.

The typical recorded voltammograms obtained in the course of Tytanit determination in Lake Zemborzyce water using procedure with preliminary mixing with Amberlite XAD-7 resin are presented in Fig. 4.

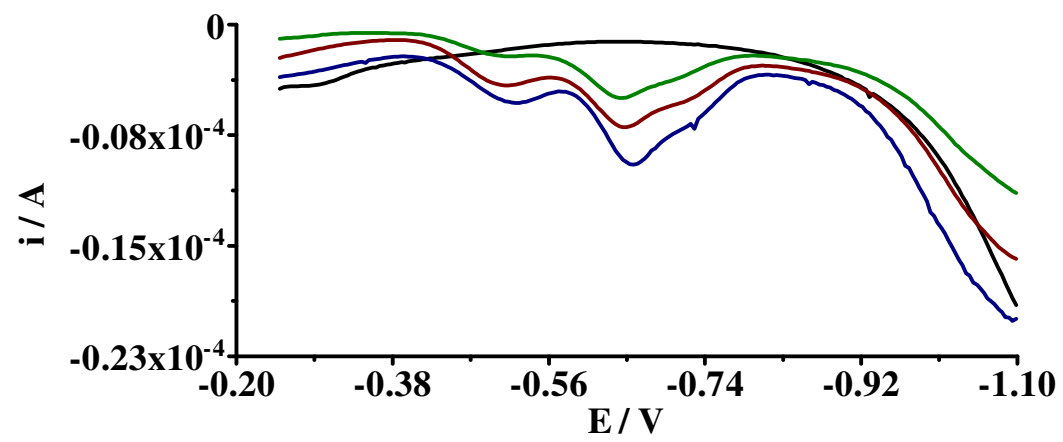

Fig. 4. Differential pulse voltammograms obtained in the course of Tytanit determination in Lake Zemborzyce water using procedure with preliminary mixing with Amberlite XAD-7 resin: diluted five-fold (black); as (black) $+3 \cdot 10^{-7} \mathrm{~mol} / \mathrm{dm}^{3}$ Tytanit (green); as (black) $+5 \cdot 10^{-7} \mathrm{~mol} / \mathrm{dm}^{3}$ Tytanit (red); as (black) $+7 \cdot 10^{-7} \mathrm{~mol} / \mathrm{dm}^{3}$ Tytanit (blue) .

\section{CONCLUSION}

An adsorptive stripping voltammetry procedure was developed for determination of $\mathrm{Ti}(\mathrm{IV})$ in Tytanit using chloranilic acid and $\mathrm{Hg}(\mathrm{Ag}) \mathrm{FE}$ as a complexing agent and a working electrode, respectively. The method is highly sensitive, selective, fast and inexpensive. Some additional information regarding the comparison this method to other analytical methods contained in previous work [5]. The procedure was directly applied for the determination of ultratrace levels of Ti(IV) derived from 
biostimulant Tytanit in natural water samples. The main novelties resulting from the proposed procedure are:

- precise investigation of the influence of different kinds of environmental water samples contained organic compounds on the titanium voltammetric signal,

- effective elimination of organic matrix interferences by using the procedure previously mixing the sample with Amberlite XAD-7 resin.

The successful practical application of the proposed procedure to the analysis of fresh natural water samples collected from eastern areas of Poland enriched with Tytanit confirms that the applied procedure is swift, simple, accurate and sensitive for the determination of titanium in environmental water samples and appears to be promising for their adoption in future environmental measurements.

\section{REFERENCES}

[1] www.tytanit.pl/file,188926,tytanit_warzywa.pdf, available: 14.12.2016.

[2] B. Król, Annales UMCS, sec. E, Agricultura, 64, 1, (2009).

[3] www.intermag.eu/tytanit-biostimulant, available: 14.12.2016,

[4] B. Baś, Anal. Chim. Acta, 570, 195, (2006).

[5] M. Grabarczyk, J. Wasąg, Talanta, 139, 132, (2015).

[6] Figure taken by the autors.

[7] A. Koper, M. Grabarczyk, J. Electroanal. Chem., 681, 1, (2012).

[8] M. Grabarczyk, Anal. Bioanal. Chem., 390, 979, (2008).

[9] A. Koper, M. Grabarczyk, J. Electroanal. Chem., 663, 67, (2011).

[10] M. Grabarczyk, J. Wasąg, Talanta, 144, 1091, (2015).

[11] M. Grabarczyk, A. Koper, Talanta, 84, 393, (2011) 